\title{
Engineering Behaviour of Sustainable Concrete with Steel Mill Scale
}

\author{
P Ganeshprabhu ${ }^{1 *}$, P Chandrasekaran ${ }^{2}$, A Sheerin Farzana ${ }^{3}$ \\ ${ }^{1}$ Department of Civil Engineering, Kamaraj College of Engineering \& Technology, \\ K. Vellakulam- 625 701, Tamilnadu, India \\ ${ }^{2}$ Department of Civil Engineering, Kongu Engineering College, Perundurai, Erode- 638052, India \\ ${ }^{3}$ Department of Civil Engineering, Kamaraj College of Engineering \& Technology, \\ K.Vellakulam- 625 701, Tamilnadu, India
}

Received: 26 March 2020

Accepted: 1 July 2020

\begin{abstract}
In the current research work steel mill scales, waste from steel industries has been tested out as a fractional replacement for sand. Steel mill scale is a waste product obtained from the steel production industries and it has an adverse effect on the environment. Steel mill scale has become a good substitute for fine aggregates in the construction industry. The experimental parameter was the percentage of steel mill scale substitution $(0 \%, 20 \%, 40 \%, 60 \%, 80 \%$ and $100 \%)$ by weight to fine aggregate content in M30 grade concrete and the results obtained from those mixes are compared with original M30 grade concrete. Compressive strength, split tensile strength, flexural strength and micro-structural characters of such concrete were evaluated. The interaction of steel mill scale within the concrete has been methodically investigated using micro-structural studies. It was found that very small particle size of steel mill scale fills the voids between the fine and coarse aggregate thus makes dense concrete. The test outcomes suggest that recycling steel mill scale by utilizing as a fractional replacement for fine aggregate offers a viable cost effective and environmentally friendly solution at $60 \%$ replacement.
\end{abstract}

Keywords: waste product, sustainable concrete, waste management, steel mill scale, river sand, compressive strength, split tensile strength, flexural strength, SEM

\section{Introduction}

In the present Indian context, there is a growing necessity in minimizing the usage of natural river sand in concrete production. In this regard, the construction industry has previously captivated various

*e-mail: gp.civil@yahoo.in industrial waste as a substitute for natural aggregates. The consumption of construction aggregates all over the world, in terms of volume, is likely to attain 62.9 billion metric ton by the end of 2024, up from 43.3 billion metric ton in 2016 [1]. Natural sand demand in India reached 950 million metric ton in 2015 from 300 million metric ton in 2000 [2]. It is expected to reach 1430 million metric ton in 2020. According to the report, sand will experience the maximum demand in India. As the living standards of the human beings 
increase continuously, the demand of natural resources also increases. Therefore, it is essential to find an alternate material for sand.

India ranks the third position in steel manufacturing all over the world and hence huge amount of wastes gets generated annually. India was third-largest steel producer in 2016 across the world. India produced 95.6 million metric ton of crude steel during 20162017. This growth is due to convenience, cost effective labour and availability of raw materials. However, iron and steel manufacturing accompanies with the creation of solid waste materials like slag, steel mill scale, etc. Indian steel plants produce nearly 29 million ton of unwanted materials yearly. In order to achieve sustainability, one possible solution is to use the waste constituents again as secondary resources. Several attempts at researching this issue were already made using slag and foundry sand.

Three waste products (foundry sand, steel mill scale, and slag) of the iron and steel production industries can be used in concrete. During the steel processing work, steel mill scale forms on the surface of the metal. Steel mill scale is obtained all through casting and hot rolling process and they are detached by water sprays. This non-recyclable steel mill scale can be used in concrete as an iron source.

However, the steel mill scales of non-recyclable category have not been researched much for its beneficial use in concrete. The steel mill scales are produced as a result of scrubbing of the oxidized steel sections. These steel mill scales are generated in large volumes in steel manufacturing units. However, it is hardly recycled due to the very low recovery potential. Steel mill scale is as an exportable material and is free from duties whereas Iron ore export draws 30\% duty. During the past 3 years, steel mill scale exports in India have been increased by $71 \%$ to 1.2 Million Ton. These steel mill scales are generally used in the cement manufacturing facilities as a source of iron. Nevertheless, there have not been wider reports of commercial exploitation of steel mill scales in concrete preparation.

The use of countless industrial trashes in concrete production can avoid the problem of their disposal and all at once encourage the production of sustainable construction ingredients. Metal industry slag can be used to produce fast hardening concrete since they contribute to increase the cement hydration process [3]. The presence of $\mathrm{SiO}_{2}, \mathrm{Al}_{2} \mathrm{O}_{3}$ and calcium oxides in steel sludge and steel slag yield positive improvement in flexural and compressive strength when they were used as a binder in concrete [4]. Steel slag contains more Dicalcium and Tricalcium Silicate in active form which helps to increase the hydration of cement. Hence steel slag is used as partial replacement for river sand gives better compressive behavior than normal concrete [5, 6]. Concrete made from iron and steel industrial wastes can be used as a shielding structure against gamma radiation [7].
Billet scale, a by-product from steel rolling mill, can be utilized in concrete as a fractional substitute for fine aggregate. Concrete mechanical properties proportionately increased for all \% replacement of fine aggregate [8]. Presence of silicates in pulverized steel mill scale will help to build pozzolanic nature in it, when it is partially replaced with cement in concrete [9]. Steel mill scale has the capacity to be evaluated as a substitute for river sand in concrete. Different experiments on consumption of this steel mill scale waste from iron industry have been conducted in concrete on its partial substitution for fine aggregates [10]. Mechanical strength properties produce better results for the concrete contains coarse steel mill scale aggregate [11]. The usage of mill scale and steel scrap as a supernumerary material for river sand in concrete production is extremely beneficial and effective compared to the utilization of nonrenewable resources [12]. The addition of steel mill scale aggregate in concrete does not cause shrinkage or expansion in concrete. Use of steel scale aggregate in concrete possesses good compressive strength, decreases water absorption and improves apparent density. Integration of steel mill scale as partial fine aggregate replacement produces dense micro-structure to the concrete [13]. Steel mill scales are finer particles than sand with high specific gravity. Hence, steel mill scale can be utilized to produce high density concrete [14]. The mechanical strength of mortar samples rises with the partial substitution of steel mill scale for fine aggregate. The high specific gravity of steel mill scale will help to produce denser concrete when it is partially substituted for fine aggregate [15]. The irregular shape of steel mill scale creates a strong interlocking with cement mortar and thus leads to increase in concrete's compressive strength [16]. High roughness of steel mill scale creates a strong adhesion between the scale and the cement paste thus contributes to the enhancement of mechanical and fracture properties [17]. The main constituents of steel mill scale are iron oxides, magnesium oxide, alumina and silica [13, 14, 16, 17]. The presence of hematite, magnetite and other oxides of calcium and aluminium in steel mill scale yields positive improvement in compressive and flexural strength when they were utilized in concrete as a fine aggregate [14, 16]. Utilization of steel mill scale in construction industry as fine aggregate reduces the solid wastes disposal into environment $[12,16]$.

After a meticulous collection of information, though some researchers have testified the use of trash materials and some by-product as fine aggregates only minimal research focus on utilization of steel mill scale as fine aggregate in concrete. This investigation is therefore executed to assess the probable use of steel mill scale as sand replacement in concrete production. The intent of this research is to scrutinize the feasibility of utilization of steel mill scale as a substitute to raw sand in varying proportions on concrete strength properties. 
Table 1. Composition of cement.

\begin{tabular}{|c|c|}
\hline Properties & Test result \\
\hline Consistency & $31 \%$ \\
\hline Specific gravity & 3.15 \\
\hline Initial setting time & $31 \mathrm{~min}$ \\
\hline Final setting time & $171 \mathrm{~min}$ \\
\hline Compressive strength: 7 Days & $29.92 \mathrm{~N} / \mathrm{mm}^{2}$ \\
\hline Compressive strength : 28 Days & $34.12 \mathrm{~N} / \mathrm{mm}^{2}$ \\
\hline Soundness- Le chatelier & $1 \mathrm{~mm}$ \\
\hline
\end{tabular}

\section{Materials and Methods}

\section{Cement}

Branded Portland Pozzolonic Cement (PPC) purchased from the local market was used as binding material. Recently manufactured cement without hard lumps was used to produce good quality concrete. The physical, as well as the chemical characteristics of the cement, were tested as per IS: 4031-1991 and it is presented in Table 1.

\section{Fine Aggregate}

Existing local river sand which is available nearby is utilized as fine aggregate. This river sand used in this study conforms to Zone II. The sand passed through $4.75 \mathrm{~mm}$ sieve was used. The requirements of the aggregates were experimented as per IS: 383-1970. The test results of the physical and chemical compositions of the river sand are tabulated in Table 2 and Table 3.

\section{Coarse Aggregate}

Natural locally available clean angular coarse aggregate was used. It was sieved through $20 \mathrm{~mm}$ sized sieve. The aggregate passed through $20 \mathrm{~mm}$ sieve and retained on $4.75 \mathrm{~mm}$ sieve was utilized in this study. The specific gravity of the aggregate used was 2.75 .

\section{Water}

Clean Water must be used for the concrete and it must be free from impurities like solid particles, oil and acids. Portable water available in the laboratory is used for casting and curing the concrete specimens.

\section{Steel Mill Scale}

Steel mill scale, a by-product from steel processing work, was collected from the industries and utilized in partial manner to replace fine aggregate. Steel mill scale was selected as a fractional alternative for fine aggregate. Steel mill scale mainly consists of oxides of iron, aluminium, calcium and some silica. The physical and chemical composition of the steel mill scale was shown in Table 2 and Table 3. The steel mill scale has higher specific gravity than that of fine aggregate.

\section{SEM Analysis of Sand and Steel Mill Scale}

The mechanical properties of sand and steel mill scale are governed by their inherent microstructure. The intrinsic micro-structure features are primarily affected by the particle dimension, shape, its distribution and topographical defects such as voids, cracks. The Scanning Electron Microscopy (SEM) provides a noteworthy role in solving the topographic of sand and steel mill scale.

SEM images of the sand and steel mill scale with different magnification were studied. Fig. 1a) and Fig. 1b) show the shape of the sand particle and steel mill scale. It clearly show that the sand particles are angular in shape with rocky morphology and the steel mill scales are irregular in shape.

Similarly, Fig. 2a) and Fig. 2b) show the surface texture of the sand particle and steel mill scale. Surface texture of a material is characterised by its surface roughness and surface unevenness. From Fig. 2a) and Fig. 2b), it is clear that steel mill scale has very rough

Table 2. Physical composition of Sand and Steel mill scale.

\begin{tabular}{|c|c|c|c|c|c|}
\hline Characteristics & Specific Gravity & Bulk Density (g/cc) & $\begin{array}{c}\text { Bulking of Sand } \\
(\%)\end{array}$ & $\begin{array}{c}\text { Relative density } \\
(\%)\end{array}$ & Void Ratio \\
\hline Sand & 2.43 & 1.67 & 16.28 & 36.36 & 0.76 \\
\hline Mill Scale & 4.007 & 2.36 & 10.29 & 61.19 & 0.62 \\
\hline
\end{tabular}

Table 3. Composition details of Sand and Steel mill scale.

\begin{tabular}{|c|c|c|c|c|c|c|}
\hline Characteristics & $\begin{array}{c}\text { Loss on } \\
\text { Ignition }\end{array}$ & $\begin{array}{c}\text { Silica } \\
\left(\mathrm{Sio}_{2}\right)\end{array}$ & Iron $\left(\mathrm{Fe}_{2} \mathrm{O}_{3}\right)$ & $\begin{array}{c}\text { Aluminum Oxide } \\
\left(\mathrm{Al}_{2} \mathrm{O}_{3}\right)\end{array}$ & $\begin{array}{c}\text { Calcium Oxide } \\
(\mathrm{CaO})\end{array}$ & $\begin{array}{c}\text { Magnesium } \\
(\mathrm{MgO})\end{array}$ \\
\hline Sand & 1.24 & 79.93 & 4.4 & 10.92 & 1.18 & 1.66 \\
\hline Mill Scale & 4.29 & 4.58 & 72.55 & 31.44 & 1.53 & 0.99 \\
\hline
\end{tabular}


a)

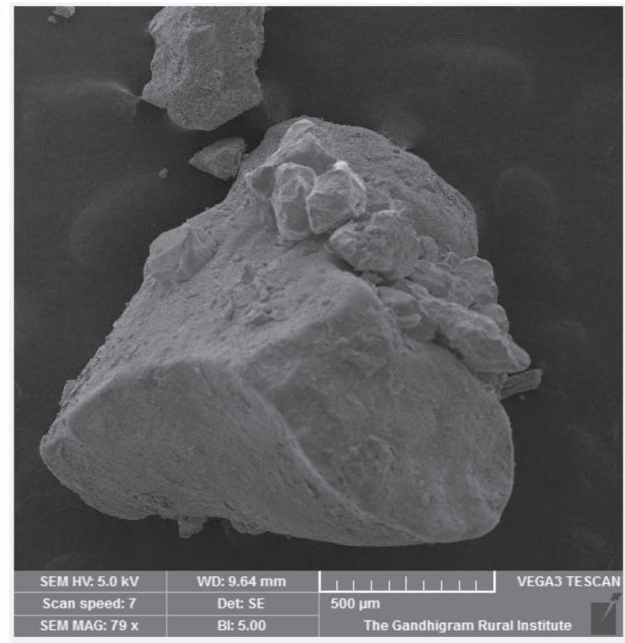

b)

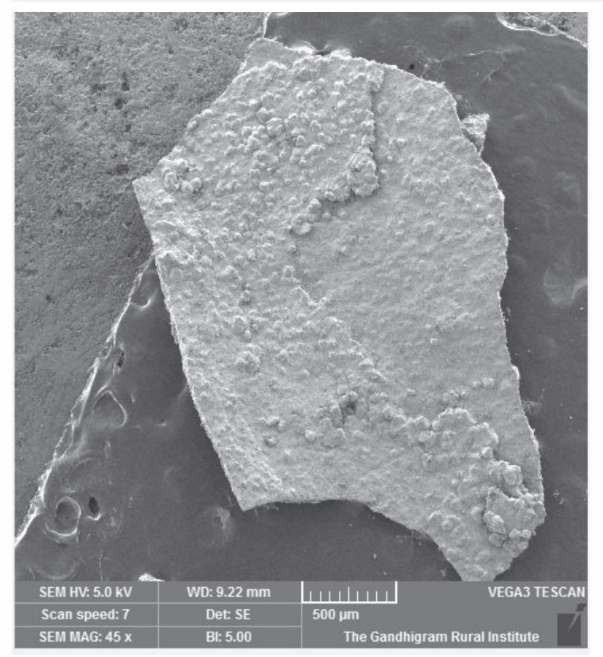

Fig. 1. SEM images showing shape of sand and steel mill scale.

surface compared to sand particles. Due to surface roughness and irregular shape, steel mill scale can easily make its binding with the concrete and is recommended for various construction applications [16, 17].

\section{EDAX Analysis of Steel Mill Scale}

Mineral constituents in steel mill scale was obtained and mapped from EDAX results. It is seen from Fig. 3 that there is a significant content of alumina and iron fraction present in the steel scale [16-18]. These results are in agreement with chemical composition of steel mill scale (Table 3). The presence of alumina and iron in the steel mill scale will positively contribute to the formation of Bogue's compound during hydration of cement. Oxides of iron and alumina present in steel mill scale may react with silica present in fine aggregate to form C-S-H gel.

\section{Particle Size Distribution of Sand and Steel Mill Scale}

The particle size distribution of sand replaced with various percentage of steel mill scale was found out. a)

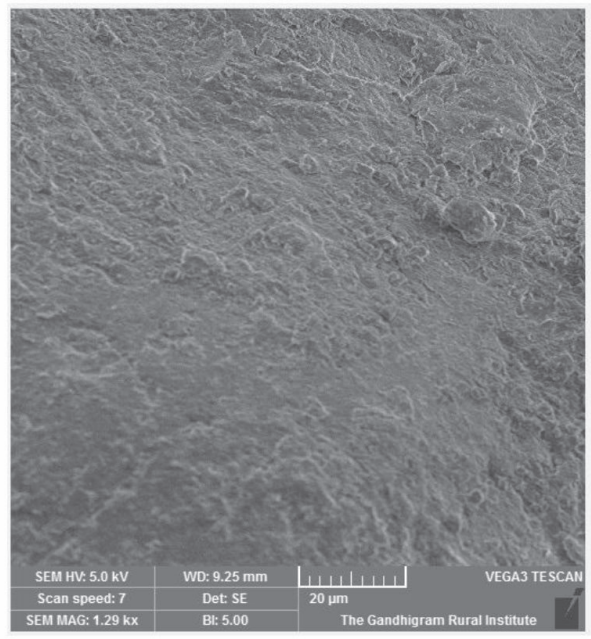

b)

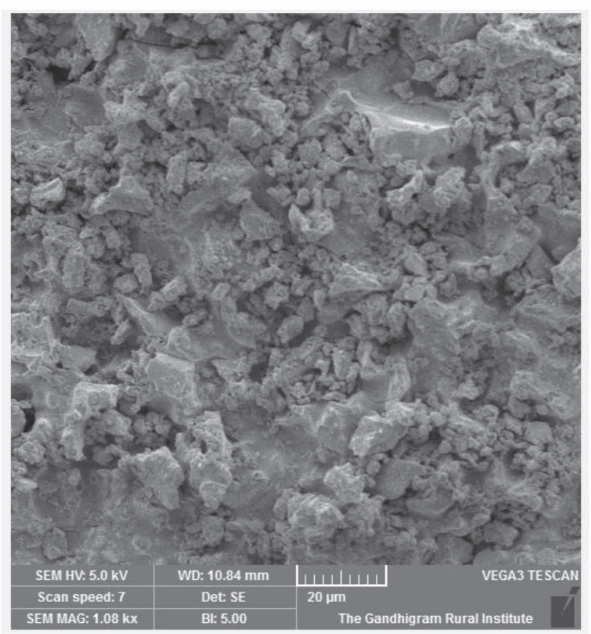

Fig. 2. SEM images showing surface texture of sand and Steel mill scale.

The fine aggregate grading curve obtained for various levels of steel mill scale replacement is as shown in Fig. 4.

As it may be seen from Fig. 4, the inclusion of steel mill scale did not alter the overall grading curve of fine aggregate significantly. The fineness modulus of partially replaced sand with steel mill scale was

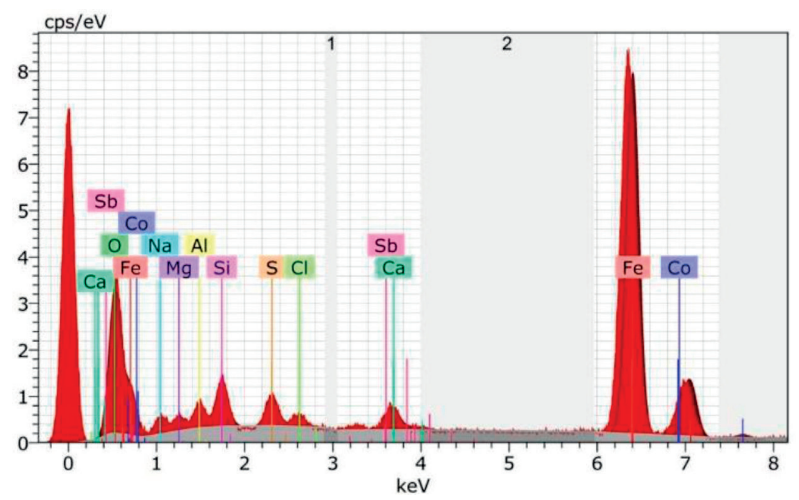

Fig. 3. EDAX mapping of constituents in steel mill scale. 


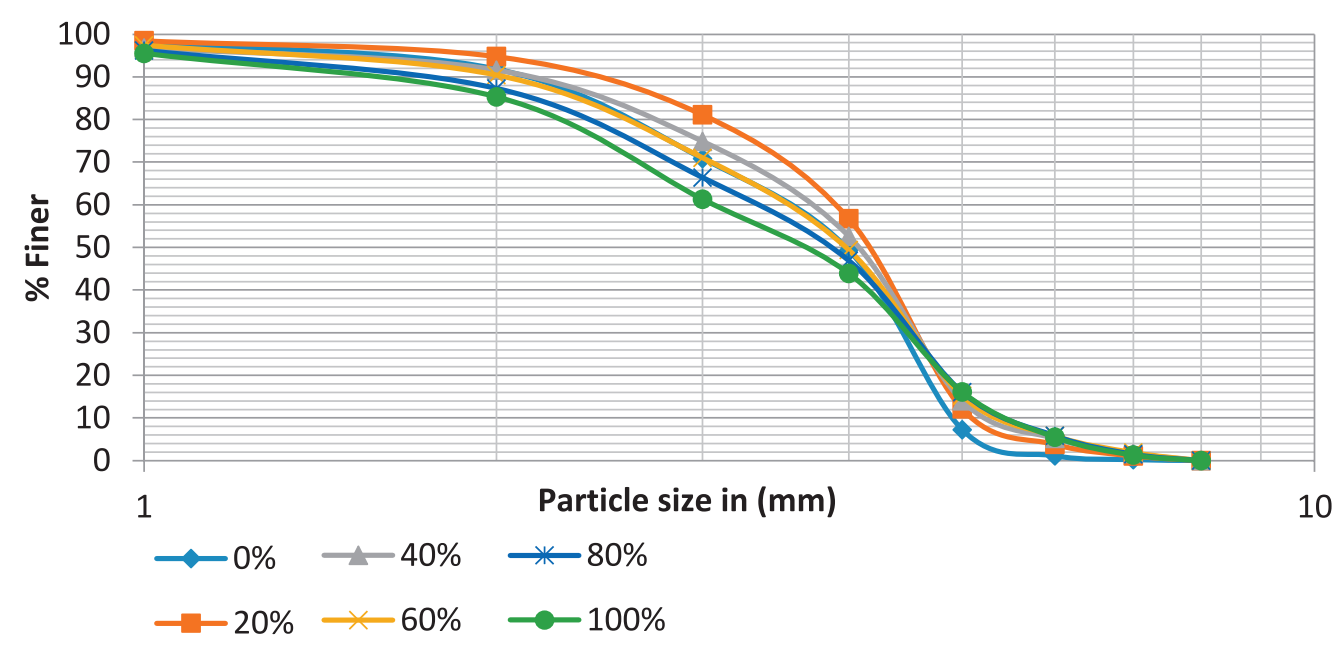

Fig. 4. Particle size distribution curve for fine aggregates and steel mill scale.

shown in Table 4. From the Table 4, it is clear that steel mill scale resembles the properties of natural sand. Incorporation of such steel mill scale in natural aggregate will not vary fineness modulus of fine aggregate. The shift in fineness modulus for pure sand and sand blended with steel mill scale were within 0.4 even for very high fractions of replacements.

\section{Specimen Preparation}

\section{Mix Design}

In order to investigate the impact of steel mill scale replacing fine aggregate partially, a number of experimental trials were conducted. The control specimen was designed for a target strength of M30 as per the Indian concrete Mix design code IS 10262-2009. The steel mill scale proportions were increased in fixed intervals of $20 \%$. The design mix proportion used in the study was 1:1.457:3.202 (Cement: Fine aggregate: Coarse aggregate) and a w/c ratio of 0.5 is adopted.

\section{Concrete Specimen}

$150 \mathrm{~mm}$ X $150 \mathrm{~mm}$ X $150 \mathrm{~mm}$ sized cubes and $150 \mathrm{~mm}$ diameters and $300 \mathrm{~mm}$ height cylinders were cast. Concrete prisms of $500 \mathrm{~mm} \mathrm{X} 100 \mathrm{~mm} \mathrm{X}$ $100 \mathrm{~mm}$ size were also cast. Fine aggregate in concrete was partially replaced with steel mill scale. Steel mill scale was replaced in different percentages like $0 \%$, $20 \%, 40 \%, 60 \%, 80 \%$ and $100 \%$ respectively. Three numbers of specimens were cast for each replacement.
The aggregates, steel mill scale and cement were first dry mixed. After that, water was added to the blend and were mixed well. The concrete was placed into the mould in 3 layers and each layer was being thoroughly compacted. The moulds were left undisturbed for 24 hours in ambient conditions. The specimens were unmoulded and were water cured for a period of 28 days.

\section{Experimental Procedure}

Concrete workability tests were conducted as per IS: 1199-1959 code. To study the steel mill scale impact on concrete strength, hardened concrete properties like compressive, split tensile and flexural strengths were determined. All the strength tests were done on three specimens for each replacement level. The compressive and split tensile strengths were determined as per IS: 516-1959 and IS: 5816-1999. The specimens were tested with a loading rate of $5 \mathrm{kN} / \mathrm{min}$.

\section{Workability Test}

The workability of the concrete mixes was measured with the help of slump test and compaction factor test. Concrete was tested for workability as soon as the concrete was mixed. The slump cone was packed in three layers and tamped for 25 times with a steel rod. The cone is then removed and the decrease in concrete height is measured. In order to determine the compaction factor, the concrete mix is filled in the upper hopper and allowed to drop into the lower hopper and then to bottom cylinders with the help of trap

Table 4. Comparison of fineness modulus of partially replaced sand with steel mill scale.

\begin{tabular}{|c|c|c|c|c|c|c|}
\hline$\%$ Replacement & $0 \%$ & $20 \%$ & $40 \%$ & $60 \%$ & $80 \%$ & $100 \%$ \\
\hline Fineness Modulus & 2.727 & 2.619 & 2.708 & 2.724 & 2.758 & 2.793 \\
\hline
\end{tabular}


doors. The weight of the concrete compacted partially is measured. Again, the cylinder is refilled with concrete in 3 layers; and each layer is being compacted with the help of steel rod. The weight of the fully compacted cylinder is measured. The compaction factor is then calculated as the ratio between partially and fully compacted concrete.

\section{Compressive Strength}

Concrete cube specimens were cast with the standard cube mould of size $150 \mathrm{~mm}$ X $150 \mathrm{~mm}$ X $150 \mathrm{~mm}$. For each replacement level, three samples of cubes were cast. The cubes were water cured in a curing tank for 28 days. The cube specimens were tested for compressive strength in the compressive testing machine (CTM) of $2000 \mathrm{kN}$ capacity.

\section{Split Tensile Strength}

The split tensile test of concrete was performed on $150 \mathrm{~mm}$ diameter and $300 \mathrm{~mm}$ height cylinders. The cylinders were water cured for 28 days and tested. The specimens were tested for split tensile strength in the CTM.

\section{Flexural Strength}

Flexural strength was conducted on concrete was tested using concrete prism of length $500 \mathrm{~mm}$ and $100 \mathrm{~mm}$ X $100 \mathrm{~mm}$ Cross sectional area. The specimens were cured in water cured for 28 days and tested in the Universal testing machine. The Flexural strength was determined as per IS: 516-1959.

\section{Results and Discussion}

The ease of work of the fresh concrete was tested from workability tests. The cured specimens were dried in atmosphere to eliminate the excess water and tested for various strength and micro-structural properties.

\section{Workability of Fresh Concrete}

Slump cone test and compaction factor test was done to study the workability of fresh concrete with varying replacement of fine aggregate with steel mill scale. The workability characteristics of fresh concrete get influenced by increasing percentage replacement of

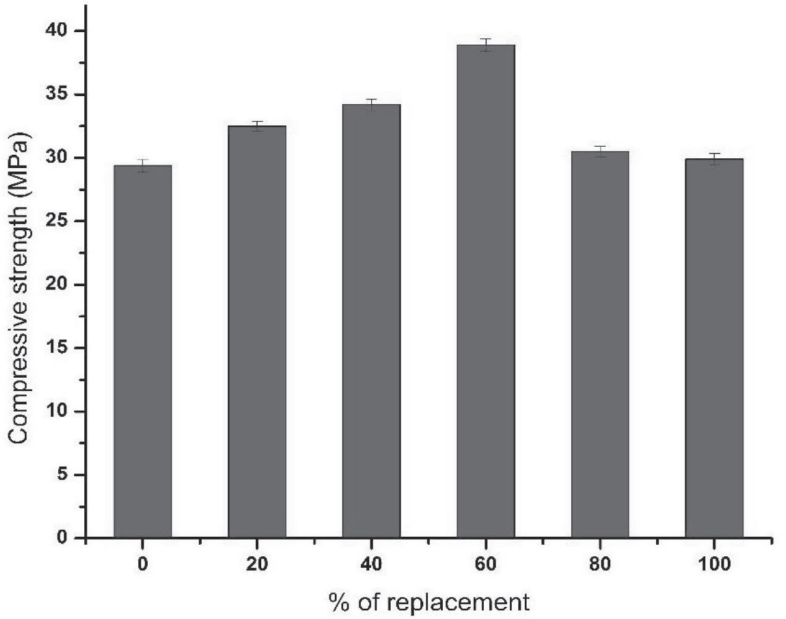

Fig. 5. Compressive strength results.

steel mill scale fraction. Table 5 shows the workability and compaction factor values observed for various levels of fine aggregate replacements.

Table 5 shows that the slump value of the mix varies from $75 \mathrm{~mm}-40 \mathrm{~mm}$ and the compaction factor value varies from 0.99 to 0.93 . From the Table 5 , it was found that workability of fresh concrete drops with increasing percentage of steel mill scale in concrete from both slump cone and compaction factor test. This drop in workability with increasing replacement levels of steel mill scale is due to the fineness of steel mill scale particles which increase the specific surface area and hence the water demand increases [15, $16]$.

\section{Compressive Strength of Concrete}

Compressive strength tests were done to identify the influence of steel mill scale in strength attainment of concrete. Compressive strength test was done on $150 \mathrm{~mm}$ size cubes and was cured for 28 days. Compressive strength mostly revealed the complete performance of the hardened concrete. The results shown in Fig. 5 were the mean made on three specimens.

As it may be seen from Fig. 5, it is found that there is a substantial rise in compressive strength as the steel mill scale content increases. The increased packing of concrete with addition to steel mill scale upsurges the density of concrete and thus contributes to the increase in compressive strength $[13,14]$. The compressive strength increases by $10.6 \%, 16.4 \%$ and $32.5 \%$ for

Table 5. Workability of concrete for various levels of steel mill scale replacement.

\begin{tabular}{|c|c|c|c|c|c|c|}
\hline \% Replacement & 0 & 20 & 40 & 60 & 80 & 50 \\
\hline Slump (mm) & 75 & 70 & 50 & 40 & 40 \\
\hline Workability & Medium & Medium & Medium & Medium Low & Low \\
\hline Compaction factor & 0.99 & 0.97 & 0.96 & 0.96 & 0.95 \\
\hline
\end{tabular}




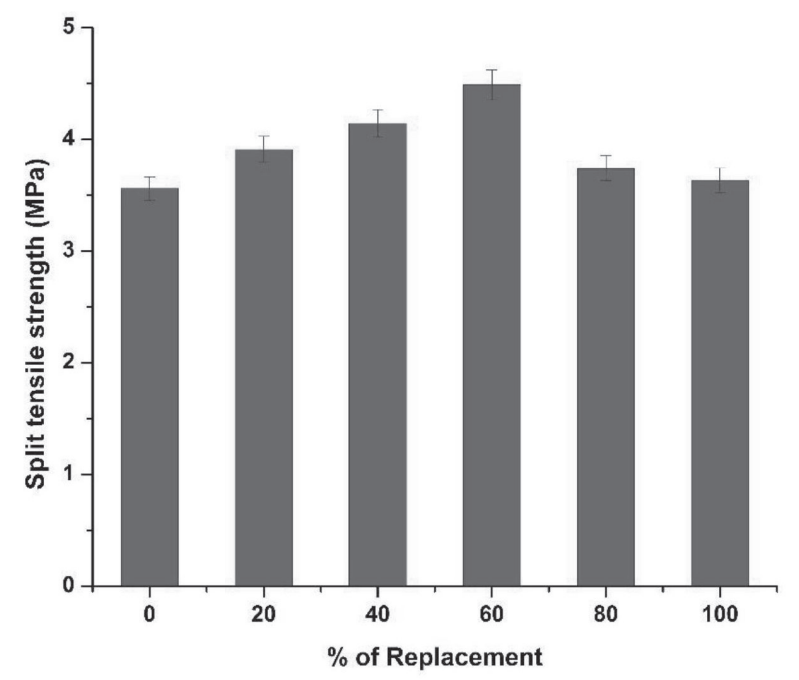

Fig. 6. Split tensile strength results.

concrete specimen having $20 \%, 40 \%$ and $60 \%$ of fine aggregate replacement with steel mill scale. The rough surface texture and high angularity of steel mill scale increase binding capacity with cement thus producing very dense concrete which obviously increases the compressive strength of concrete [13, 16, 17]. The most optimal replacement level for achieving the highest compressive strength in concrete is observed to be $60 \%$. Beyond this range, the self-weight of concrete also increases and further, due to fineness and uniform grading found in steel mill scale there is a slight drop in workability of concrete. This, in turn, prevents uniform compaction of concrete mix which causes reduction in compressive strength beyond $60 \%$ replacement [16].

\section{Split Tensile Strength of Concrete}

Fig. 6 displays the variation in split tensile strength of concrete due to the inclusion of steel mill scale. It was found that the split tensile strength rises due to the inclusion of steel mill scale. The incorporation of steel mill scale to replace of fine aggregate partially improved the split tensile strength at $20 \%, 40 \%$ and $60 \%$ replacement levels. Split tensile strength is high at $60 \%$ replacement of sand with steel mill scale. The increase in strength may be due to the chemical reaction between $\mathrm{SiO}_{2}$ content present in the steel mill scale and the cement content, thus lead to the formation of calcium silicate hydrate gel. But, further addition of steel mill scale decreases the split tensile strength of concrete, resembling the effect noticed for compressive strength. Due to its high specific gravity, the volume of the steel mill scale in the concrete mix reduces at the higher replacement levels. The decrease in volume affects the density of concrete which intern influences the split tensile strength. This decrease in strength properties of the concrete may be due to fineness of steel mill scale in concrete mix [16].

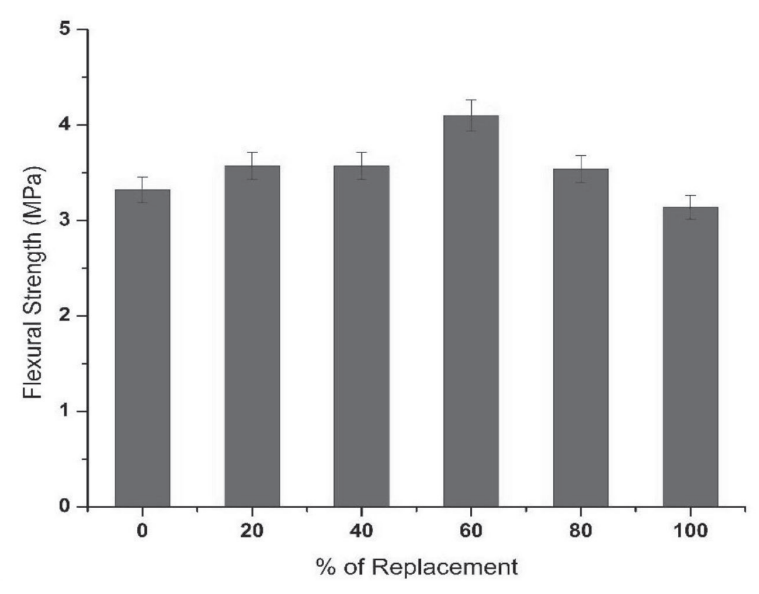

Fig. 7. Flexural strength results.

\section{Flexural Strength}

Fig. 7 represents the difference of flexural strength of concrete prism specimens. The flexural strength of control mix was $3.32 \mathrm{~N} / \mathrm{mm}^{2}$, whereas $3.52,3.59$ and $4.07 \mathrm{~N} / \mathrm{mm}^{2}$ for $20 \%, 40 \%$ and $60 \%$ replacement level of fine aggregate with steel mill scale. Flexural strength of the concrete mix increases by $5.8 \%, 7.9 \%$ and $22.5 \%$ with respect to the control mix. The increase in flexural strength may be the reason for steel mill scale high iron content which sequentially contributes to the strength. The high angularity and roughness of steel mill scale increases the flexural strength [16]. Steel mill scale particle has the tendency to deflect the crack propagation through it $[13,19]$. The flexural strength of concrete decreased after $60 \%$ replacement which resembles the compressive and split tensile strength results. The flexural strength of concrete equals to $9 \%$ of compressive strength in all the replacement levels.

\section{Micro-Structural Analysis of Hardened Concrete}

The results of micro-structure analysis concrete corresponding to $0 \%, 20 \%, 40 \%, 60 \%, 80 \%$ and $100 \%$ replacement by steel mill scale to the fine aggregate content was shown in Fig. 8.

Fig. 8 reveals that the micro-structure of the concrete cast with $0 \%, 20 \%, 40 \%, 60 \%, 80 \%$ and $100 \%$ replacement with steel mill scale were freely packed and porous. The packing density of the concrete gradually rises with the inclusion of steel mill scale. It was found that the surface of the concrete with $60 \%$ of steel mill scale was highly dense and free of pores. It was obvious that due to stiff adhesion between the particles of steel mill scale and cement mortar paste, a non-porous and continuous concrete surface was obtained at $60 \%$ replacement [17]. As the self-weight of the steel mill scale was higher than fine aggregate, the volume of steel mill scale used as fractional replacement in concrete was reduced since weigh batching method 
a)

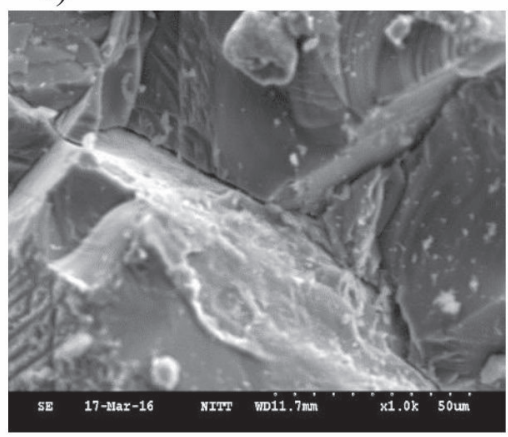

d) b)

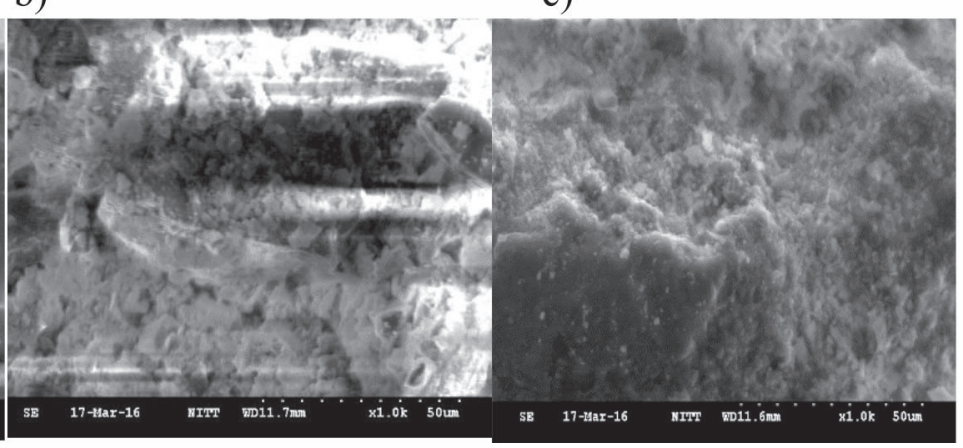

e) c)

f)

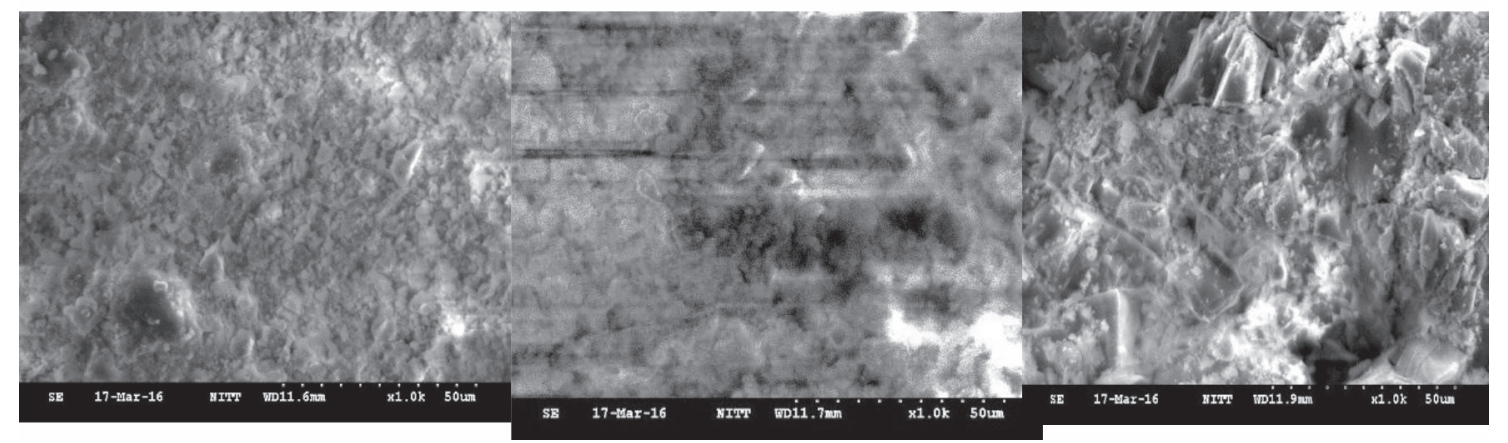

Fig. 8. SEM images of concrete obtained a) $0 \%$ replacement. b) $20 \%$ replacement. c) $40 \%$ replacement d) $60 \%$ replacement. e) $80 \%$ replacement f) $100 \%$ replacement.

is adopted. At 100\% replacement, the surface of the concrete was not dense due to the decrease in the quantity of fine aggregate in the concrete. Hence, it may be safely concluded that the steel mill scale addition does not have any retrograde effects on the C-S-H gel formation in concrete.

\section{Mechanism of Steel Mill Scale in Concrete}

From the above investigation, it may be clearly inferred that steel mill scales are very rough and fine particles with high specific gravity. It was also found that steel mill scale is rich in hematite $\left(\mathrm{Fe}_{2} \mathrm{O}_{3}\right)$ and other metal oxides of aluminium, calcium and magnesium $[13,14,16,17]$. The reaction of particle of these $\mathrm{Fe}_{2} \mathrm{O}_{3}$ present in steel mill scale with the entire quantity of calcium hydroxide crystals formed in the cement paste during hydration process may contribute to the formation of additional hydrated tri-calcium silicate gel which is thus responsible for strength of concrete. The above mentioned mechanism is in agreement with the literature [20]. The particles of iron oxide react with calcium hydroxide crystals and lead to produce additional C-S-H gel. Because of difference in specific gravity of steel mill and fine aggregate, the volume of mill scale goes on decreasing with increase in replacement levels. Hence, steel mill scale tends to segregate from the cement paste at the highest replacement levels and reduces the strength [13].
Additional research should be performed to substantiate the probable use of steel mill scale in concrete making. In the future, further research can be extended to study the contribution of other metal oxides in the development of strength in concrete. To reduce the self-weight of the steel mill scale concrete researches using lightweight materials may also be included.

\section{Conclusion}

To investigate the impact of steel mill scale as fine aggregate replacement, specimens were cast for control mix and mixes substituted with steel mill scale percentage varying from $0 \%, 20 \%, 40 \%, 60 \%, 80 \%$ and $100 \%$. Based on the investigation, the following conclusions were made:

- The workability of concrete decreases with addition of steel mill scale. It is because there is reduction in the size of fine aggregate particles which increase the specific surface and hence water demand increases.

- The replacement of steel mill scale in concrete in place of fine aggregates has been found to be viable for real-time adoption. The $60 \%$ replacement level works the best in terms of the particle grading achieved and hence the maximum strength is also obtained at this replacement level. Using steel mill scale instead of fine aggregate could extend the compressive strength of the concrete by $32.5 \%$ in 28 days. 
- The concrete made with $60 \%$ fine aggregate replacement with steel mill scales shows better micro-structural results when compared with $0 \%, 20 \%, 40 \%, 80 \%$ and $100 \%$ replacement. The concrete made with $60 \%$ of steel mill scale was densely packed and free of pores and hence shows better strength results.

- There will be no durability concerns as the particles of steel mill scales gets completely encapsulated in the concrete matrix and hence it may be adopted for practical purposes to achieve economy and environmental sustainability. More insights on durability can be obtained by conducting full-fledged durability tests.

- From the results obtained, steel mill scale can be recommended to be used in concrete to improve its mechanical and micro-structural properties, as it is environmentally safe and easily available material.

\section{Conflict of Interest}

The authors declare no conflict of interest.

\section{References}

1. India steel production to grow by $7 \%$ in 2016: Platts, Auto News, ET Auto. Retrieved March 25, 2020, from https://auto.economictimes.indiatimes.com/news/rawmaterial/india-steel-production-to-grow-by-7-in-2016platts/50951327 (n.d.)

2. Construction aggregates market 2016 - 2024 - Designing Buildings Wiki. Retrieved March 25, 2020, from https:// www.designingbuildings.co.uk/wiki/Construction aggregates_market_2016___2024 (n.d.)

3. KIRSANOVA A.A., DILDIN A.N., MAKSIMOV S.P. Influences of Steelmaking Slags on Hydration and Hardening of Concretes. IOP Conference Series: Materials Science and Engineering, 262 (1), 2017.

4. ROSLAN N.H., ISMAIL M., ABDUL-MAJID Z., GHOREISHIAMIRI S., MUHAMMAD B. Performance of steel slag and steel sludge in concrete. Construction and Building Materials, 104, 16, 2016.

5. GUO Y., XIE J., ZHAO J., ZUO K. Utilization of unprocessed steel slag as fine aggregate in normal- and high-strength concrete. Construction and Building Materials, 204, 41, 2019.

6. MO L., ZHANG F., DENG M., JIN F., AL-TABBAA A., WANG A. Accelerated carbonation and performance of concrete made with steel slag as binding materials and aggregates. Cement and Concrete Composites, 83, 138, 2017.
7. GUO Y., XIE J., ZHENG W., LI J. Effects of steel slag as fine aggregate on static and impact behaviours of concrete. Construction and Building Materials, 192, 194, 2018.

8. DIMENSION C.E. Recycling Billet Scales as Fine Aggregate in Concrete Production, 10 (2), 59, 2009.

9. OYELADE A.O., ODEGBARO D.O., FAPOHUNDA C.A. Effect of elevated temperature on the compressive strength of concrete produced with pulverized steel mill scale. Nigerian Journal of Technology, 36 (4), 1030, 2018.

10. ALWAELI M. Investigation of gamma radiation shielding and compressive strength properties of concrete containing scale and granulated lead-zinc slag wastes. Journal of Cleaner Production, 166, 157, 2017.

11. ALWAELI M., NADZIAKIEWICZ J. Recycling of scale and steel chips waste as a partial replacement of sand in concrete. Construction and Building Materials, 28 (1), 157, 2012.

12. ALWAELI M. The implementation of scale and steel chips waste as a replacement for raw sand in concrete manufacturing. Journal of Cleaner Production, 137, 1038, 2016.

13. FURLANI E., MASCHIO S. Steel scale waste as component in mortars production: An experimental study. Case Studies in Construction Materials, 4, 93, 2016.

14. MURTHY A, A., \& A, P. Indian Journal of Engineering. Indian Journal of Engineering, 14 (35), 71. Retrieved from http://www.discoveryjournals.org/engineering/current_ issue/2017/A7.pdf 2017.

15. SINGHAL A., BHUNIA D., PANDEL B. Effect of Sand Replacement By Mill Scale on the Properties of Concrete. International Journal of Engineering Technology Science and Research, 2, 60. Retrieved from http://www.ijetsr.com/ images/short_pdf/1425491811_60-67_JNU286_ijetsr.pdf 2015.

16. OZTURK M., DEPCI T., BAHCECI E., KARAASLAN M., AKGOL O., SEVIM U.K. Production of new electromagnetic wave shielder mortar using waste mill scales. Construction and Building Materials, 242, 2020.

17. KELEŞTEMUR O., ARICI E. Analysis of some engineering properties of mortars containing steel scale using Taguchi based grey method. Journal of Building Engineering, 29, 101015, 2020.

18. ÖZEN S., ŞENGÜL C., ERENOĞLU T., ÇOLAK Ü., REYHANCAN İ.A., TAŞDEMİR M.A. Properties of Heavyweight Concrete for Structural and Radiation Shielding Purposes. Arabian Journal for Science and Engineering, 41 (4), 1573, 2016.

19. DAS S., KIZILKANAT A., NEITHALATH N. Crack propagation and strain localization in metallic particulatereinforced cementitious mortars. Materials and Design, 79, 15, 2015.

20. MAHMOUD SHEIKHALESLAMZADEH S., RAOFI M. The Effect of $\mathrm{Nano}_{2} \mathrm{O}_{3}$ on the Fiber Reinforced Concrete. Research Journal of Applied Sciences, Engineering and Technology, 13 (10), 781, 2016. 
